\title{
EDUCAÇÃO ESPECIAL E FORMAÇÃO DE PROFESSORES: UMA ANÁLISE DOS PROJETOS PEDAGÓGICOS DE CURSO (PPC) ${ }^{1}$
}

\author{
EDUCACIÓN ESPECIAL Y FORMACIÓN DE LOS PROFESORES: UNA ANÁLISI DE \\ LOS PROYECTOS PEDAGÓGICOS DE CURSO (PPC)
}

\author{
SPECIAL EDUCATION AND TEACHERS TRAINING: AN ANALYSIS OF THE \\ COURSE PEDAGOGICAL PROJECT (PPC)
}

Wanessa Ferreira BORGES ${ }^{2}$

Cristiane da Silva SANTOS ${ }^{2}$

Maria da Piedade Resende da COSTA ${ }^{3}$

\begin{abstract}
RESUMO: A democratização do ensino vem impulsionando demandas de formação. Neste sentido, o artigo objetivou descrever e analisar como os cursos de Licenciatura da Universidade Federal de Goiás - Regional Catalão (RC-UFG) têm se organizado quanto à oferta de disciplinas e temáticas relacionadas à educação especial e seu público-alvo. Trata-se de pesquisa documental, que se utilizou da análise de projetos pedagógicos de curso (PPC), matrizes curriculares e ementários dos componentes curriculares de 12 cursos de licenciatura da RC-UFG, os quais foram submetidos à técnica de análise do conteúdo. Os resultados demonstram que todos os cursos investigados ofertam a disciplina de Libras, e apenas cinco oferecem disciplinas e/ou discussão de conteúdos referentes às outras especificidades da educação especial. Os dados evidenciam que apenas mediante a obrigatoriedade de oferta de conteúdos relacionados à educação especial serão atendidas as recomendações legais de formação para atendimento à diversidade.
\end{abstract}

PALAVRAS-CHAVE: Educação especial. Formação inicial. Licenciaturas.

RESUMEN: La democratización de la enseñanza viene impulsando demandas de la formación. En este sentido, el artículo objetivó describir y analizar cómo los cursos de Licenciatura de la Universidad Federal de Goiás - Regional Catalão (RC-UFG) se han organizado en cuanto a la oferta de las disciplinas y las temáticas relacionadas a la educación especial y su público objetivo. Tratase de una investigación documental, que se utilizó del analisis de proyectos pedagógicos de curso (PPC), matrices curiculares y ementários de los componentes curiculares de 12 cursos de licenciatura de la RC-UFG, los cuales fueron sometidos a la técnica de análisis del contenido. Los resultados demuestran que

${ }^{1}$ CAPES/PROEX - Processo no 23038.005155/2017-67

${ }^{2}$ Universidade Federal de São Carlos (UFSCar), São Carlos - SP - Brasil. Doutorando do Programa de Pósgraduação em Educação Especial. ORCID <http://orcid.org/0000-0002-9921-8901>. E-mail: wanessafborges@gmail.com

${ }^{2}$ Universidade Federal de Goiás (UFG), Catalão - GO - Brasil. Professora Doutora, do Departamento de Educação Física e Coordenadora do Núcleo de Acessibilidade. ORCID <http://orcid.org/0000-0002-17157229>. E-mail: crisfrutal@ hotmail.com

3 Universidade Federal de São Carlos (UFSCar), São Carlos - SP - Brasil. Professora, Doutora, do Programa de Pós-graduação em Educação Especial. ORCID <http://orcid.org/0000-0002-7420-5602>. E-mail: mariadapiedadecostac@gmail.com 
todos los cursos investigados ofrecen la disciplina de Libras, y sólo cinco ofrecen disciplinas y/o discución de contenidos referentes a las otras especificidades de la educación especial. Los datos evidencian que sólo mediante la obligatoriedad de oferta de contenidos relacionados a la educación especial serán atendidas las recomendaciones legales de formación para atención a la diversidad.

PALABRAS CLAVE: Educación especial. Formación inicial. Licenciaturas.

ABSTRACT: The education democratization has been driving training demands. In this sense, the article aimed to describe and analyze how the licentiate courses of the Federal University of Goiás - Regional Catalão (RC-UFG) have been organized regarding the offer of courses and themes related to special education and its target audience. This documentary research was carried out using the analysis of the course pedagogical project (PPC) syllabuses and curricular components of 12 licentiate courses at RC-UFG, which were submitted to the content analysis technique. The results show that all the courses investigated offer the Brazilian Sign Language discipline and only five offer disciplines and/or discussion of contents related to the other special education specificities. The data show that only through the obligation to offer content related to special education the legal recommendations of training to attend to diversity will be met.

KEYWORDS: Special education. Initial training. Licentiate degree.

\section{Introdução}

A adoção de um novo posicionamento filosófico, ideológico e político quanto à democratização do ensino básico causou transformações consideráveis na realidade escolar. Entre estas transformações destacaremos a presença em sala de aula comum do ensino regular de alunos público-alvo da educação especial. Segundo dados do Censo, a matrícula de alunos público-alvo da educação especial em salas de aula comum do ensino regular saltou de aproximadamente 81000 no ano de 2000 para 796486 em 2016 (INEP, 2017).

Este aumento é resultado do movimento das reformas educacionais e suas normativas legais iniciadas principalmente a partir da década de 1990, dentre as quais destacamos a Constituição Federal de 1988 (BRASIL, 1988), as Diretrizes e Bases da Educação Nacional Lei n. 9394/96 (BRASIL, 1996), a Política Nacional de Educação Especial na Perspectiva Inclusiva (BRASIL, 2008), que estabelecem o direito de todos à educação, garantindo a possibilidade de acesso às pessoas com deficiência, transtornos globais do desenvolvimento e altas habilidade/superdotação à escola comum. Desde então, a crescente presença destes alunos na escola vem impulsionando demandas de formação, seja de professores de educação especial, seja de professores do ensino regular, que em colaboração devem auxiliar no processo de inclusão escolar (SANTOS, 2012). 
Contudo, estudos que tratam do processo de inclusão escolar dos alunos público-alvo da educação especial no ensino regular apontam que os professores não se sentem preparados para efetivarem tal processo (VITALIANO; MANZINI, 2010; ALVES; DUARTE, 2014; NOZI; VITALIANO, 2017). A falta de capacitação profissional ainda se apresenta como umas das maiores dificuldades vivenciadas pelos professores para promoverem a inclusão (ALVES; DUARTE, 2014), atribuindo o despreparo à ausência de disciplinas ou discussões sobre inclusão e/ou educação especial durante sua formação inicial (VITALIANO; MANZINI, 2010).

Nesse sentido, considerando que os professores são os principais agentes de mudança, "um dos aspectos importantes para a construção de escolas para todos é, sem dúvida, a formação dos professores” (RODRIGUES, 2014 apud NOZI; VITALIANO, 2017, p. 591). Vários instrumentos jurídico-normativos preveem a formação de professores para atenderem a essa nova demanda de alunos e incumbem as instituições de ensino superior de desenvolverem competências e habilidades no futuro licenciado (POKER; MELLO, 2016).

Desde 1994, o Ministério da Educação (MEC), através da Portaria 1.793, recomendou a inclusão da disciplina “Aspectos ético-políticos-educacionais da normalização e integração da pessoa portadora de necessidades especiais" prioritariamente nos cursos de Pedagogia, Psicologia e demais licenciaturas (BRASIL, 1994). Em 1999, o Decreto 3.298 orientava tratamento prioritário quanto à formação de professores na área da educação especial.

Em 2001, o Conselho Nacional de Educação publicou o Parecer nº 9, recomendando a organização dos cursos de formação de professores. Em relação às exigências de formação que atendam às demandas dos paradigmas inclusivos, o documento afirma:

[...] a educação básica deve ser inclusiva, no sentido de atender a uma política de integração dos alunos com necessidades educacionais especiais nas classes comuns dos sistemas de ensino. Isso exige que a formação dos professores das diferentes etapas da educação básica inclua conhecimentos relativos a educação destes alunos (BRASIL, 2001, p. 16)

Seguindo na mesma direção da orientação supracitada, em 2002 foram publicadas as Diretrizes Curriculares Nacionais para a Formação de Professores da Educação Básica por meio da Resolução CNE/CP $\mathrm{n}^{\circ} 1$ de 2002 (BRASIL, 2002), as quais indicam que as instituições de ensino superior devem prever, em sua organização curricular, a formação docente para o atendimento à diversidade, contemplando conhecimentos sobre as especificidades dos alunos público-alvo da educação especial. 
Em 2005, o Decreto nº 5.626 prevê a inserção da Língua Brasileira de Sinais (Libras) como disciplina curricular obrigatória nos cursos de formação de professores para o exercício do magistério, em nível médio e superior, e nos cursos de Fonoaudiologia de instituições de ensino públicas e privadas (BRASIL, 2005).

Em 2015, a inclusão de disciplinas/conteúdos curriculares é reforçada no Art. 28, incisos XIV da Lei Brasileira de Inclusão (Lei n. 13.146/2015), abrangendo todos os cursos de nível superior e de educação profissional técnica e tecnológica, não se restringindo apenas aos cursos de licenciaturas (BRASIL, 2015b). Ademais, as Diretrizes Curriculares Nacionais para a formação inicial em nível superior e para a formação continuada (RESOLUÇÃO $\left.\mathrm{CNE} / \mathrm{CP}^{\circ}{ }^{\circ} 2,2015\right)$ orientam que os cursos de formação deverão garantir nos currículos:

conteúdo específicos da respectiva área de conhecimento ou interdisciplinares, seus fundamentos e metodologias, bem como conteúdos relacionados aos fundamentos da educação, formação na área de políticas públicas e gestão da educação, seus fundamentos e metodologias, direitos humanos, diversidades étnico-racial, de gênero, sexual, religiosa, de faixa geracional, Língua Brasileira de Sinais (Libras), educação especial e direitos educacionais de adolescentes e jovens em cumprimento de medidas socioeducativas (BRASIL, 2015a).

Baseando-se nessas recomendações, Pureza (2012) se propôs a analisar os Projetos Pedagógicos (PPP) dos cursos de licenciaturas em Geografia das instituições de ensino superior públicas de Belém-Pará. Suas análises se pautavam em identificar se os PPPs, ao construírem sua proposta curricular, contribuíam para a formação de professores na perspectiva inclusiva de acordo com as competências previstas na legislação brasileira. $\mathrm{O}$ autor identificou que o PPP do curso de Geografia da Universidade Federal do Pará (UFPA) trata os termos educação especial e educação inclusiva como sinônimos, restringindo as potencialidades e a amplitude da educação inclusiva. Já O Instituto Federal do Pará (IFPA) apresenta uma concepção de educação inclusiva capaz de desenvolver um atendimento escolar à diversidade e à diferença, proporcionando, através de disciplinas e experiências in locus, a relação teórico-prática necessária para preparar o professor para o contexto escolar inclusivo.

Pedroso, Campos e Duarte (2013), ao analisarem as matrizes curriculares dos cursos de licenciatura de três universidades públicas localizadas no interior do estado de São Paulo, constataram que nenhuma ementa apresentou conteúdos sobre educação especial, embora a disciplina de Didática de apenas um dos cursos tenha indicado em seus objetivos gerais a 
preparação dos alunos para a compreensão crítica e contextualizada do papel da escola e do trabalho docente.

Nesta mesma perspectiva de pesquisa, Basso (2015), ao analisar a formação inicial de professores da área de Ciências (Biologia, Física e Química) voltada para a educação inclusiva/educação especial nos cursos de licenciaturas nas universidades públicas estaduais do estado de São Paulo, constatou a presença das temáticas investigadas em apenas três projetos políticos pedagógicos, bem como sua pouca inserção em disciplinas da área pedagógica. A autora destaca ainda que, segundo a percepção dos licenciandos, os fatores que mais dificultam a inclusão escolar são a formação dos professores e a infraestrutura escolar.

Assim, observamos que, embora haja inúmeras orientações na legislação, as pesquisas revelam que as instituições de ensino superior não têm atendido às recomendações legais. $\mathrm{A}$ este respeito, Poker e Mello (2016), ao discorrerem sobre as demandas advindas dos postulados da Política Nacional de Educação Especial na perspectiva da Educação Inclusiva (BRASIL, 2008), afirmam que fica evidente, do ponto de vista político, que os professores egressos dos cursos de licenciatura precisam estar capacitados para ensinarem aos alunos constantes da demanda atual da escola. Todavia, não está do mesmo modo evidente, seja nas normativas legais vigentes, seja nas propostas de investimentos em formação, a preocupação explícita com o desenvolvimento dos conhecimentos necessários para a adequação do trabalho educacional com os alunos público-alvo da educação especial.

Assim, partindo da premissa de que todo professor atuará com esta demanda específica constatada por direito, é que problematizamos: como os cursos de licenciatura da Regional Catalão da Universidade Federal de Goiás (RC/UFG) têm se organizado para prepararem os futuros professores para atuarem em salas de aulas do ensino regular com alunos público-alvo da educação especial?

A fim de responder à presente questão de pesquisa, o artigo objetivou descrever e analisar como os cursos de Licenciatura da Universidade Federal de Goiás - Regional Catalão têm se organizado quanto à oferta de disciplinas e temáticas relacionadas à educação especial e seu público-alvo, através dos Projetos Pedagógicos de Curso, grades curriculares e ementários.

\section{Metodologia}

Para viabilizar o alcance dos objetivos propostos neste estudo, foi considerado pertinente o desenvolvimento de um estudo descritivo, seguindo a metodologia de pesquisa 
qualitativa, a qual se embasou na pesquisa documental. Segundo Salvador (1986), esse tipo de estudo se caracteriza pela análise particular de documentos já consolidados selecionados pelo pesquisador, a fim de que se possam obter dados específicos mediante consulta a documentos, que são previamente definidos pelo pesquisador, na tentativa de encontrar subsídios para análises alicerçadas nos objetivos iniciais.

Desse modo, o 'corpus' do trabalho foi constituído pelos Projetos Pedagógicos de Curso (PPC) e pelas as Matrizes Curriculares e/ou os Ementários dos Componentes Curriculares dos cursos de graduação na modalidade licenciatura da RC/UFG. A RC/UFG oferece atualmente 20 diferentes cursos de graduação, destes, 13 (treze) são na modalidade licenciatura e 7 na modalidade Bacharelado. Para seleção dos cursos que fariam parte do 'corpus' de pesquisa adotamos os seguintes critérios de inclusão: a) ser ofertado na modalidade Licenciatura; b) ser curso presencial; c) ter acesso a pelo menos um dos documentos de fontes de dados. Os 13 (treze) cursos de licenciatura da RC/UFG são: Ciências Biológicas, Ciências Sociais, Educação do Campo, Educação Física, Física, Geografia, História, Letras - Português, Letras - Português/Inglês, Matemática, Pedagogia, Psicologia e Química.

A coleta de dados se deu inicialmente no 'site' da instituição (menu 'Resoluções'), em que usamos o nome dos cursos como descritores para busca do PPC com resoluções aprovadas pelo Conselho de Ensino, Extensão e Cultura da UFG, e com este procedimento de coleta encontramos 7 PPC. Em seguida, pesquisamos os 'sites' dos cursos de graduação (apenas para os cursos de graduação que não encontramos o PPC no 'site' da UFG) e encontramos 3 (três) PPC, 2 (duas) Matrizes Curriculares e 1 (um) Ementário dos Componentes Curriculares. Mas, visando padronizar a análise de dados e obter todos os documentos de todos os cursos, entramos em contato com a Coordenação de Graduação da Regional Catalão e com os coordenadores dos cursos de Pedagogia, Educação do Campo, Psicologia (tínhamos apenas a matriz e ementário dos Componentes Curriculares) e Química. Obtivemos retorno do curso de Pedagogia, que nos enviou por e-mail o PPC, e da Coordenação de Graduação, que nos enviou a matriz curricular dos cursos de Psicologia (já tínhamos), Química e Pedagogia (a Coordenação enviou o PPC). O quadro 1 ilustra os documentos e as fontes de coleta de dados. 
Quadro 1 - Fonte documental de pesquisa e lócus de coleta dos documentos.

\begin{tabular}{|c|c|c|c|}
\hline Cursos & Ano & Documentos & Fonte de coleta \\
\hline Ciências Biológicas & 2017 & PPC* & Site UFG - menu Resoluções \\
\hline Ciências Sociais & 2012 & & \\
\hline Educação Física & 2016 & & \\
\hline Geografia & 2009 & & \\
\hline História & 2013 & & \\
\hline Matemática & 2009 & & \\
\hline Letras - Port. & 2011 & $\mathrm{PPC}^{*}$ & Site dos cursos de graduação. \\
\hline Letras - Inglês & 2011 & & \\
\hline Física & 2013 & & \\
\hline Pedagogia & 2017 & $\mathrm{PPC}^{*}$ & Contato com coordenador. \\
\hline Psicologia & - & $\begin{array}{l}\text { Matriz Curricular e Ementário } \\
\text { dos componentes Curriculares }\end{array}$ & Página do curso (site). \\
\hline Química & - & Matriz curricular & $\begin{array}{l}\text { Solicitação à } \\
\text { Graduação da } \\
\text { mail. }\end{array}$ \\
\hline Educação do Campo & - & - & - \\
\hline
\end{tabular}

$(*)$ Nos PPC estão inclusos as Matrizes Curriculares e os Ementários dos componentes Curriculares. Fonte: Elaboração própria a partir de dados da pesquisa.

Considerando os critérios de inclusão, apenas o curso de Educação do Campo não fez parte do 'corpus' da pesquisa, pois não tivemos acesso a nenhum dos documentos para análise.

Analisamos a fonte documental buscando identificar temáticas relacionadas à educação especial e seu público no aporte teórico que fundamenta a elaboração do documento. As Matrizes Curriculares foram analisadas visando identificar disciplinas relacionadas à educação especial e seu público-alvo, e, finalmente, os Ementários dos Componentes Curriculares foram analisados na perspectiva de encontrarmos a temática em disciplinas específicas ou de forma transversal, compondo parte dos conteúdos a serem trabalhados.

Os dados extraídos dos documentos foram organizados e sistematizados em planilhas, em que destacamos as seguintes informações: temas relacionados à educação especial na tessitura textual do PPC; carga horária total dos cursos; disciplinas relacionadas à educação especial/inclusão escolar e seu público alvo e/ou que incorporassem a temática, e suas respectivas cargas horária, identificação do núcleo e natureza; informações no ementário que indicassem a discussão da temática, considerando ementa, objetivos e bibliografias. Optamos por analisar os dados utilizando a técnica de análise do conteúdo descrita por Bardin (2004).

\section{Resultados e discussão}


Ao analisarmos a parte teórica que fundamenta a elaboração dos PPC dos cursos de licenciatura da RC/UFG apenas os cursos de Ciências Biológicas, Educação Física, Física, História e Pedagogia (n=5) dos 12 cursos analisados fazem menção a algum aspecto da educação especial. Em comum, os cinco cursos citam em suas bases legais e regulamentam o proposto no Decreto $\mathrm{n}^{\circ} 5.626$, de 22 de dezembro de 2005, que dispõe sobre a obrigatoriedade da oferta da disciplina de Libras aos cursos de Licenciatura e Fonoaudiologia.

Além desses aspectos, os cursos de Ciências Biológicas, Educação Física e Pedagogia apresentam as seguintes semelhanças quanto à seleção e explicitação das normativas que basearam a elaboração dos PPC: a) Resolução CNE/CP $n^{\circ}$ 2, de 2015, que dispõe sobre a garantia nos currículos de conteúdos relacionados à educação especial, Libras e outras áreas do conhecimento que não são objeto desta pesquisa; b) Lei n. 12.764, de 27/12/2012, que dispõe sobre a proteção dos direitos da Pessoa com Transtorno do Espectro Autista (TEA); c) referência ao Núcleo de Acessibilidade e Inclusão (NAI) como oferta de recursos e serviços a acadêmicos público-alvo da educação especial.

Apesar de citarem normativas em comum, cada curso se organiza de maneira diferente. Em relação à garantia dos conteúdos na grade curricular, o curso de Educação Física apresenta, em sua fundamentação teórica, a presença de um eixo de formação que atravessa toda a matriz curricular e incorpora conteúdos relacionados à educação especial, além da oferta da disciplina "Educação Física Adaptada", que surgiu oficialmente nos cursos de graduação em Educação Física através da Resolução n. 03/87 do Conselho Federal de Educação. Em contraposição, o curso de Ciências Biológicas apenas cita a necessidade de garantir os conteúdos de educação especial, mas, em sua fundamentação teórica, não há referências sobre como será atendido o previsto na Resolução CNE/CP n. 2/2015. O PPC do curso de Pedagogia menciona a referida diretriz como documento basilar em sua elaboração, mas não há inferências diretas no seu discurso teórico ao artigo 14 , inciso VI, $\S 2^{\circ}$, como fazem os PPC de Educação Física e Ciências Biológicas. Apesar disso, ao longo do seu texto é destacada a importância da formação do professor para a educação e a inclusão, afirmando contemplar em sua organização curricular quatro disciplinas obrigatórias (Educação Especial e Inclusão; Libras; Estágio em Educação Especial I e II) e três disciplinas eletivas (Aquisição da Língua Brasileira de Sinais e alfabetização, Educação e diferenças e Inclusão Escolar) relacionadas à área da educação especial/educação inclusiva.

Quanto à Lei $n^{\circ} 12.764$ de 2012, que dispõe sobre a proteção dos direitos da pessoa com TEA, o curso de Ciências Biológicas se propõe a abordar a temática nas disciplinas de Psicologia da Educação I e Psicologia da Educação II; já o curso de Educação Física afirma 
que o tema será tratado na disciplina Educação Física Adaptada, e o curso de Pedagogia, por sua vez, alega que será abordado nas disciplinas Educação Especial e Inclusão e Estágios Curriculares do Curso, espaço/tempo no qual o discente de Pedagogia poderá encontrar alunos com Transtornos do Espectro Autista (TEA), e, ainda, acusa a possibilidade de oferta de disciplinas como núcleo livre que contemplem a temática.

E o último aspecto comum aos três cursos foi a indicação do NAI na oferta de serviços e recursos para garantir o ingresso e a permanência de acadêmicos com deficiência, transtornos globais do desenvolvimento e altas habilidades/superdotação que venham a ingressar nos referidos cursos de graduação.

Acerca da democratização do ensino há que se distinguir e considerar dois preceitos: o primeiro se refere à adoção, por parte das instituições de ensino superior, de políticas públicas que garantam o ingresso, a permanência e a formação profissional dos seus graduandos, independente da sua condição física, sensorial, intelectual ou motora (MOREIRA; BOLSANELLO; SEGER, 2011); e o segundo diz respeito ao compromisso das instituições em formar professores capacitados para atenderem à diversidade de alunos presentes na escola atual, respeitando e atendendo às mais variadas necessidades (UNESCO, 1994).

Assim, ao considerarmos PPC dos cursos de Ciências Biológicas, Educação Física e Pedagogia podemos afirmar que em sua tessitura textual contemplam dois preceitos fundamentais da inclusão: preveem recursos e serviços de acessibilidade para permanência e aprendizagem de alunos público-alvo da educação especial nos seus cursos de graduação, e preocupam-se com a habilitação de professores para efetivarem a inclusão na educação básica.

Além dos aspectos em comum acerca da educação especial e seu público abordados pelos PPCs na sua fundamentação teórica e estrutural, o curso de Pedagogia comtempla outros pontos, tais como: a) a infraestrutura e a acessibilidade para pessoas com deficiência na RC/UFG; b) a atuação ativa na formação inicial e continuada de professores na área da educação especial e inclusão; e c) as políticas de inclusão social da instituição.

No que se refere à infraestrutura e à acessibilidade, são descritas as adaptações arquitetônicas e estruturais que viabilizam o acesso da pessoa com deficiência, citando a presença de elevadores e amplas escadas nos blocos didáticos, passarelas que interligam os prédios com rampas de ultrapassagem de desníveis, sanitários adaptados, reserva de vagas no estacionamento, e a recente reforma que visa tornar o espaço da instituição acessível às pessoas com deficiência. Além dos aspectos arquitetônicos e urbanísticos, o PPC prevê a oferta de serviços do NAI para tornar os materiais didáticos, pedagógicos e comunicacionais 
acessíveis. E, ainda, menciona o Laboratório do Núcleo de Pesquisa e Práticas Educativas e Inclusão (Neppein) como espaço onde são desenvolvidas pesquisas na área de educação especial.

O curso de Pedagogia deixa explícito o seu compromisso com a formação inicial dos seus discentes para atuarem na área de educação especial, com a oferta de disciplinas obrigatórias, optativas e estágio na área. Segundo o PPC, é objetivo do curso desenvolver saberes, competências e habilidades que permitam ao futuro pedagogo atuar na educação de estudantes público-alvo da educação especial em diferentes contextos: classe comum, serviços de apoio e atendimento a esses estudantes. Além dessas ações, são descritas iniciativas que colaboram e/ou colaboraram com a formação continuada dos professores, por meio da oferta de cursos de especialização lato sensu, e de uma linha de pesquisa específica que discute a educação e os direitos da pessoa com deficiência no programa de Pós-Graduação em Educação (stricto sensu). O surgimento desta linha de pesquisa é apresentado no PPC como derivação da atuação do grupo de pesquisa "Núcleo de estudos e pesquisa de práticas educativas e inclusão" (Neppein), que desenvolve projetos de pesquisa e extensão desde 1999 com os discentes do curso de Pedagogia.

Quanto às políticas de inclusão social da UFG relacionadas ao público-alvo da educação especial, o PPC do curso de Pedagogia afirma que são previstas a reserva de 15 vagas no curso de Letras- Libras (Regional Goiânia) para estudantes surdos, não havendo reservas de vagas para as outras demandas da educação especial, e nem mesmo em outros cursos.

Ao analisarmos as matrizes curriculares e os ementários dos componentes curriculares, percebemos dois tipos de organização curricular nos cursos que ofertam disciplinas relacionadas à temática da educação especial e seu público-alvo: disciplinas que tratam especificamente da temática e inserção de conteúdos e discussões relacionadas aos conteúdos da educação especial nas ementas, objetivos e/ou bibliografia (Quadro 2). 
Quadro 2 - Relação de disciplinas (diretamente ou indiretamente) relacionadas à educação especial e inclusão escolar nos cursos de licenciatura presenciais da RC/UFG.

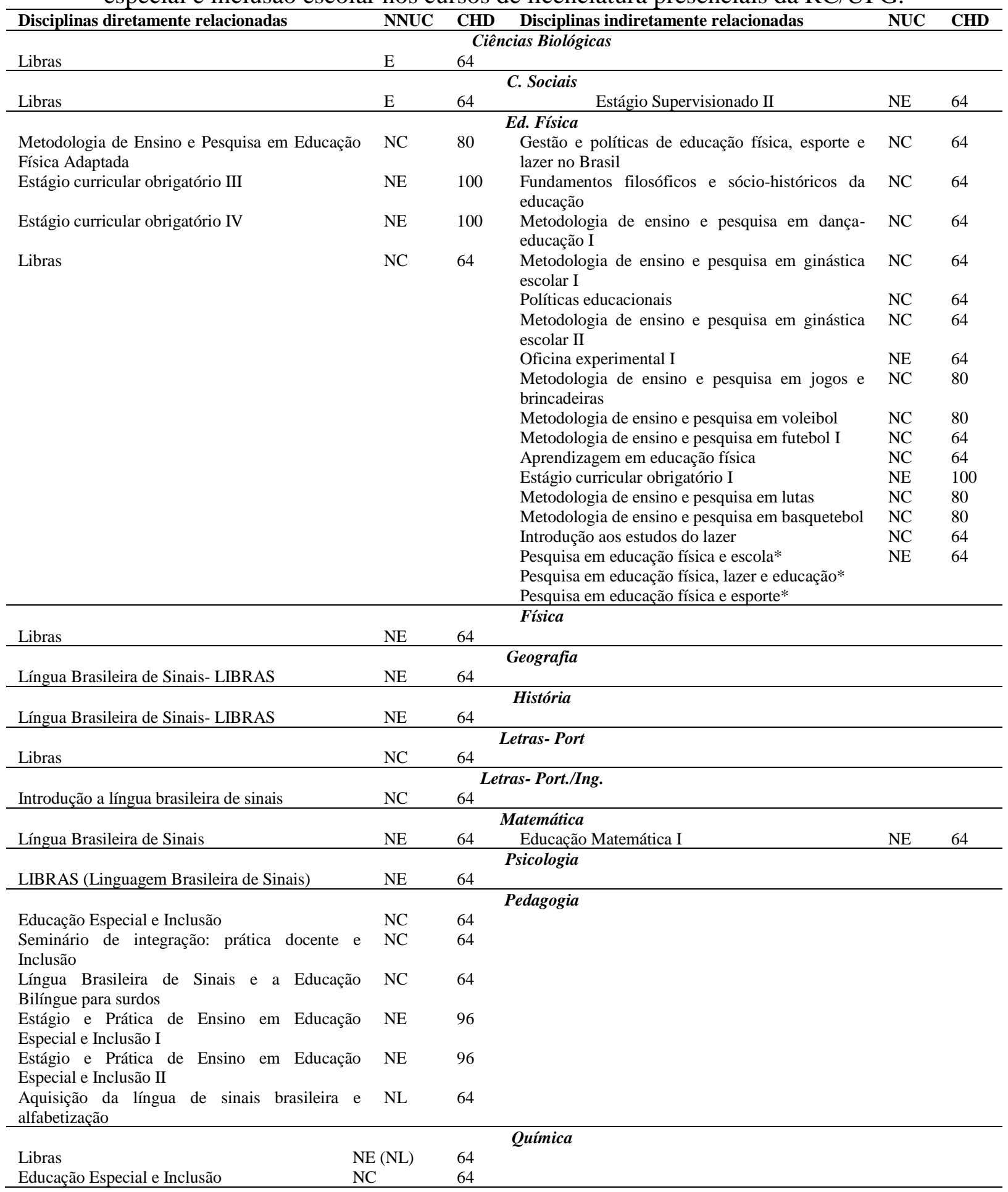

Fonte: Projetos Político Pedagógico, Matrizes Curriculares e Ementário dos componentes Curriculares dos cursos de licenciatura da RC/UFG.

Legenda: CHD- Carga Horária Disciplina; NUC- Núcleo; NE- Núcleo Específico; NC- Núcleo Comum; NL- Núcleo Livre.

O Quadro 2 nos mostra que os 12 cursos de licenciatura oferecem a disciplina de Libras aos graduandos, embora apenas cinco tenham mencionado o Decreto 5.626 de 2005 na 
fundamentação teórica do PPC. Esse dado é reflexo da obrigatoriedade de oferta desta disciplina aos cursos de licenciatura e fonoaudiologia prevista em lei. Apesar da obrigatoriedade, o curso de Psicologia oferece a disciplina com natureza optativa, o que pode estar relacionado à habilitação do curso - Bacharelado e Licenciatura - e não exclusivamente licenciatura.

A questão que se levanta é que as disciplinas optativas (Núcleo Livre) estão condicionadas aos interesses individuais dos discentes e à disponibilidade do docente em oferecer a disciplina regularmente. Conforme Silva (2009), preocupar-se-ão em cursá-la apenas aqueles discente que já tiveram algum contato ou interesse subjacente à disciplina.

\footnotetext{
Assim, restringe a formação e informações importantes a um pequeno grupo que, por motivos diversos, já possuíam algum contato com a temática. A grande maioria que, também, tornar-se-á professor (a) e, na sua vida cotidiana, em sala de aula, irá demandar de conhecimentos elementares desta questão não os terá, nem mesmo, orientações de onde encontrá-los. Sendo esta uma demanda transferida para a sua formação continuada. (SILVA, 2009, p. 188-189, grifos nossos)
}

A natureza optativa na oferta da disciplina de Libras no curso de Psicologia deixa os discentes que não se interessam em cursá-la sem nenhuma formação na área da educação especial e seu público-alvo. Em geral, mesmo ante a obrigatoriedade, ao compararmos os dados aqui apresentados com os de outras pesquisas, é possível inferir o avanço da RC/UFG quanto ao cumprimento do decreto de obrigatoriedade da oferta de Libras, já que diversas pesquisas apontam a ausência da oferta até mesmo desta disciplina nos cursos de licenciatura pesquisados (PEDROSO; CAMPOS; DUARTE, 2013; RIBEIRO, 2011; BASSO, 2015).

Já os cursos de Educação Física (3), Pedagogia (5) e Química (1) dispõem de disciplinas específicas que irão subsidiar a capacitação do professor de classe comum no atendimento ao aluno público-alvo da educação especial. Entre as disciplinas específicas, o curso de Educação Física e Pedagogia oportunizam aos discentes a formação prática para o atendimento a estas demandas por meio de estágios em educação especial.

Além da oferta de disciplinas específicas, os cursos de Ciências Sociais, Educação Física e Matemática contemplam conteúdos e eixos temáticos relacionados à educação especial em outras disciplinas. Ao analisarmos os ementários dos componentes curriculares verificamos que em 18 deles do curso de Educação Física a educação especial e a inclusão escolar são previstas como ponto de discussão no processo formativo, contudo, não identificamos referências bibliográficas especificamente relacionadas a este objetivo em nenhuma das disciplinas que se propuseram a discutir a temática. Todavia, a ausência de 
referências bibliográficas específicas não significa que autores mencionados na bibliografia básica e complementar não abordem aspectos da educação especial. Já os cursos de Ciências Sociais e Matemática destinam uma disciplina em que a temática se faz eixo de discussão e foram constatadas referências que atendem ao objetivo que é proposto na ementa.

Segundo Amaral et al. (2000, p. 9),

se fossem incluídos tópicos sobre a deficiência nos diversos cursos de formação (como propõe o documento do MEC e a legislação brasileira), os nossos profissionais já poderiam ter ultrapassado a barreira do desconhecimento que, muitas vezes, é a matéria-prima de atitudes preconceituosas. Mas sempre é tempo!.

Conforme analisa Silva (2012, p. 15):

[...] se não houver a introdução nos currículos de situações que apresentem uma discussão sobre as diferenças, sobre a discriminação e o preconceito, sobre as diferentes formas de experimentar a condição humana, promovendo uma modificação conceitual, a concretização da inclusão continuará sendo distanciada do cenário da educação superior, e mesmo da educação básica, pois os profissionais que lá atuam são formados nestes cursos. $\mathrm{O}$ conhecimento é um aliado de qualquer processo que prime pela modificação da realidade.

Neste sentido, podemos inferir que os egressos dos cursos de licenciatura da RC/UFG têm em sua formação o contato pelo menos com a disciplina Libras. É claro que nem a carga horária da disciplina Libras, nem mesmo o contato com apenas uma das inúmeras temáticas da educação especial capacitam estes professores a lidarem com a diversidade do público da educação especial. Todavia, a barreira do desconhecimento da área está quebrada pela garantia da oferta dessa disciplina em todos os cursos investigados, bem como de disciplinas e/ou conteúdos que discutem a educação especial e/ou a inclusão escolar das demais especificidades da educação especial nos cursos de Ciências Sociais, Educação Física, Matemática, Química e Pedagogia.

Ao confrontarmos os dados da fundamentação teórica, as matrizes curriculares e os ementários dos componentes curriculares, verificamos que a transversalidade prevista na fundamentação teórica do PPC de Educação Física foi identificada em 18 disciplinas. Em contraposição, o curso de Ciências Biológicas apenas cita a necessidade de garantir os conteúdos de educação especial, mas, ao organizar a grade curricular, só oferta a disciplina Libras, não havendo nenhuma outra disciplina acerca das demais especificidades do públicoalvo da educação especial e nem mesmo conteúdos ou eixos que discutam a educação especial 
incorporados a outras disciplinas. O curso de Pedagogia, por sua vez, prevê quatro disciplinas obrigatórias e três eletivas em sua fundamentação teórica, contudo, na matriz curricular e ementários encontramos cinco disciplinas obrigatórias que abordam o tema e uma disciplina de natureza optativa que se constitui como núcleo livre aos estudantes da instituição.

No que se refere à lei de proteção ao direito da pessoa com TEA, ao analisarmos a ementa e a bibliografia básica e complementar das referidas disciplinas não identificamos a inclusão da temática nas disciplinas de Psicologia da Educação I e II; já na disciplina de Educação Física Adaptada encontramos referência à temática na ementa, a qual se propõe a discutir o contexto histórico-social e características desta população, assim como dos demais alunos público-alvo da educação especial, enquanto as disciplinas de Educação Especial e Inclusão e Estágio e Prática de ensino em Educação Especial e Inclusão I e II se propõem a discutir a educação e a inclusão dos alunos com transtornos globais do desenvolvimento.

A indicação feita no PPC do curso de Ciências Biológicas de que as disciplinas de Psicologia da Educação I e II abordariam a temática do autismo, e que as proposições de inserção de conteúdos relacionados à educação especial subsidiariam a organização curricular não se confirmaram ao analisarmos as ementas, objetivos e bibliografias, o que nos permite inferir que estes documentos legais são colocados no PPC apenas para atender às normativas de elaboração do mesmo, não fundamentando a formação do futuro professor, já que não estão presentes na grade curricular, ementas e bibliografias, com exceção da Libras.

Diante disso, questionamos até que ponto os aspectos citados nos PPC não estão presentes apenas para atender aos requisitos legais da construção do documento ou de avaliações dos cursos. Veiga (2003) destaca que, muitas vezes, a construção dos PPC acontece apenas com base nas regulamentações propostas em nível nacional que devem ser incorporadas aos projetos pelas instituições de ensino. Contudo, esse processo desconsidera uma construção coletiva e ideológica, não refletindo o interesse do grupo que o implementará, o que resulta na não efetivação do proposto no documento.

Para ilustrarmos graficamente o percentual de carga horária que aborda a temática em relação à carga horária total do curso apresentamos a Figura 1. Ao observarmos, é possível perceber que 48,8\% da carga horária do curso de Educação Física se destina, em algum momento, a discutir a educação especial, a inclusão escolar e/ou seu público-alvo. Já o curso de Pedagogia destina aproximadamente $14 \%$ da sua carga horária especificamente à formação de seus alunos na área de educação especial. Os cursos de Ciências Sociais, Matemática e Química reservam, respectivamente, 3,9\%, 4,2\% e 3,8\% à preparação dos egressos para 
atuarem com o público-alvo da educação especial, enquanto os demais cursos reservam em média 1,9\% para oferecer formação em Libras aos seus alunos.

Figura 1 - Percentual de carga horária de disciplinas que abordam a educação especial/inclusão escolar em relação a carga horária total dos cursos de licenciatura da RC/UFG.

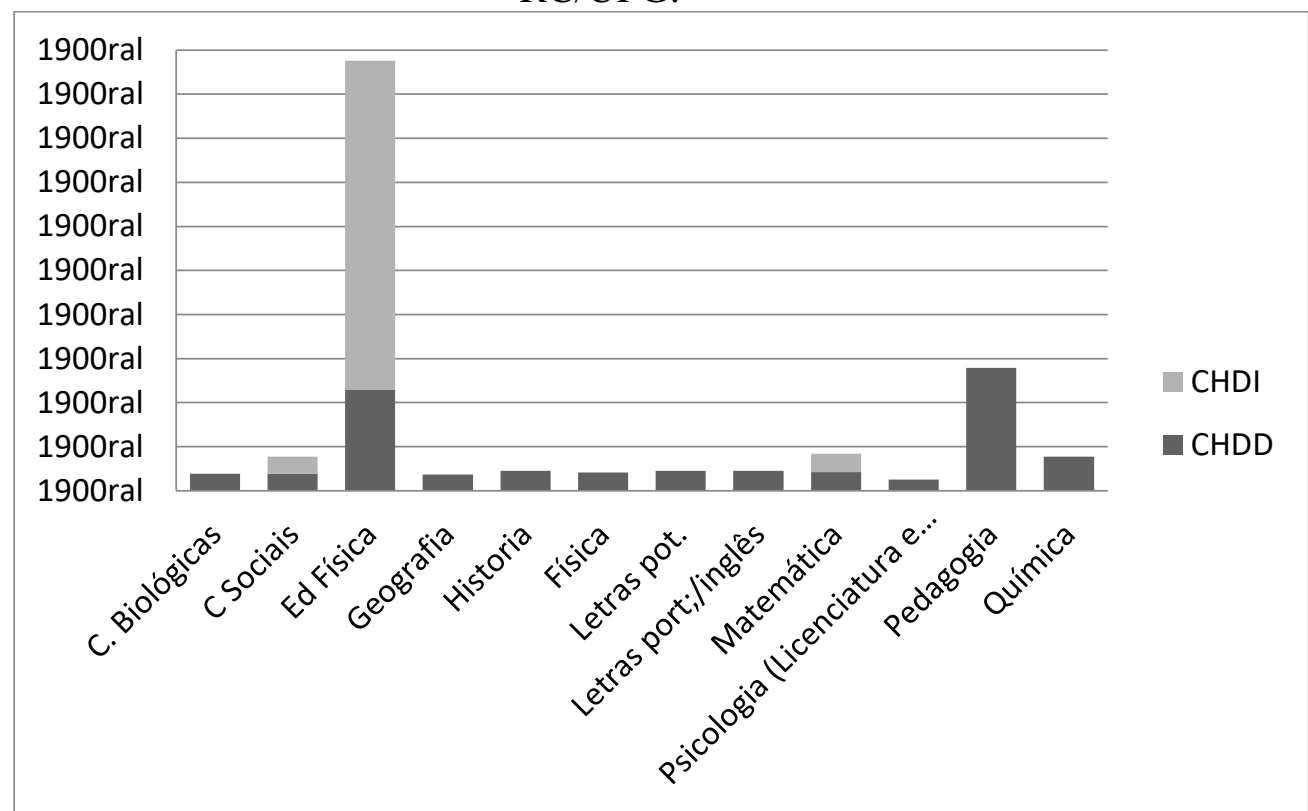

Fonte: Elaboração própria a partir de dados da pesquisa.

De maneira geral, percebemos grandes avanços em relação ao compromisso com a formação de professores nos cursos de Educação Física e Pedagogia. Estes avanços podem ser justificados pela atuação ativa do curso de Educação Física desde 1987 no que se refere ao público-alvo da educação especial; no caso da Pedagogia, os avanços podem ser reflexos das pesquisas desenvolvidas pelo Neppein desde 1999, que geralmente apontam para a falta de formação de professores como principal causa do fracasso dos alunos da educação especial (CARDOSO, 2013; SILVA, 2014; BORGES, 2015).

Avanços nesses cursos também foram apontados nos estudos de Vitaliano e Manzini (2010), os quais analisaram 13 cursos de Licenciatura da Universidade Estadual de Londrina e identificaram que o Curso de Educação Física, além de uma disciplina específica, contempla essa discussão por meio de tópicos específicos em outros conteúdos curriculares. Os autores destacam ainda que esses conteúdos devem ser contemplados no ensino, pesquisa, extensão, grupos de estudos, bem como se deve proporcionar aos(às) alunos(as) do curso experiências/vivências em estágios com vistas a aproximar o egresso do curso com a realidade dos espaços de atuação que tenham as pessoas com deficiência inseridas. (VITALIANO; MANZINI, 2010). 
Assim, são evidentes os avanços na formação inicial de professores da RC/UFG, mas, ao considerarmos que apenas cinco dos 12 cursos investigados apresentam disciplinas e/ou inserção de conteúdos, além da específica da surdez com a oferta da Libras, podemos inferir que há muito o que avançar para conseguirem responder às demandas de inclusão escolar na educação básica.

\section{Considerações finais}

A partir dos objetivos propostos no estudo verificamos algumas contradições entre o discurso presente na parte teórica do PPC no que se refere à discussão sobre a educação especial e seu público-alvo e a incorporação dessa discussão em sua organização curricular. Outro fato é a presença da disciplina Libras em todos os cursos analisados, tendo em vista a obrigatoriedade de um decreto e a presença de conteúdos sobre a educação especial em apenas 5 cursos, sendo que há recomendação dessa inclusão há 23 anos pela Portaria n $^{o}$ $1.793 / 1994$.

Neste sentido, os dados nos mostram que somente mediante a obrigatoriedade da oferta de disciplinas da educação especial, como ocorre com a Libras, é que há uma real efetivação do que se propõe nos documentos legais, pois, embora haja inúmeras recomendações quanto à inserção de conteúdo ou ofertas de disciplinas que preparem o futuro professor para atuar com o aluno público-alvo da educação especial, isto só se efetivou em cinco cursos. Portanto, considerando a gritante demanda apontada pelas pesquisas, faz-se necessário rever as recomendações e dar a estas caráter obrigatório, de modo que possa ser garantida a oferta de pelo menos uma disciplina obrigatória especificamente relacionada à educação especial, e a transversalidade da discussão nas demais disciplinas.

Desta feita, no contexto investigado não podemos desconsiderar os avanços dos cursos investigados, principalmente os cursos de Educação Física e Pedagogia, que têm contemplado essa temática no ensino, pesquisa, estágios e grupos de estudos. Como limitação do presente estudo destacamos que: as análise foram apenas documentais e não tivemos acesso às disciplinas de núcleo livre, já que sua oferta é dinâmica. Assim, sugerimos para próximos estudos verificar a materialização do que está previsto nos documentos analisados na formação dos licenciados e dos professores formadores e que sejam investigados os núcleos livres, de forma a identificar se esta formação têm se dado por meio destas disciplinas.

\section{REFERÊNCIAS}


ALVES, M. L. T; DUARTE, E. A percepção dos alunos com deficiência sobre a sua inclusão nas aulas de educação física escolar: um estudo de caso. Revista Brasileia de Educação Física do Esporte, São Paulo, p. 329-338, abr./jun. 2014.

AMARAL, L. A. et al. Projeto USP legal propondo uma política da USP referida à deficiência. 2000. Disponível em:

www.fsp.usp.br/acessibilidade/cd/atiid2003/.../ProjetoUSPLegal.doc. Acesso em: 30 nov. 2010.

BARDIN, L. Análise do conteúdo. Lisboa- Portugal: Ed.70, 2004. 223p.

BASSO, S. P. S. Curso de licenciatura na área de Ciências: a temática inclusão escolar de alunos com necessidades educacionais especiais. 2015. 131f. Tese (Doutorado em Educação) - Programa de Pós-Graduação em Educação para a Ciência, Universidade Estadual Paulista

“Julio de Mesquita Filho", Bauru, 2015.

BORGES, W. F. Tecnologia Assistiva e Práticas de Letramento no Atendimento Educacional Especializado. 2015. 205 f. Dissertação (Mestrado em Educação) - Programa de Pós-graduação em Educação, Universidade Federal de Goiás - Regional Catalão, Catalão, 2015.

BRASIL. Constituição da República Federativa do Brasil. Brasília: Senado Federal, 1988. Disponível em: http://www.culturabrasil.pro.br/zip/constituicao.pdf. Acesso em: 6 fev. 2011.

BRASIL. Decreto n. 5626 de 22 de dezembro de 2005. Regulamenta a Lei n. 10436 de 24 de abril de 2002 que dispõe sobre a Língua Brasileira de Sinais e o art.18 da Lei 10.098 de 19 de dezembro de 2000.2005. Disponível em: www.planalto.gov.br/ccivil_03/_Ato20042006/2005/Decreto/D5626.htm. Acesso em: 6 fev. 2011.

BRASIL. Lei no 13.146, de 6 de julho de 2015. Lei Brasileira de Inclusão da Pessoa com Deficiência (Estatuto da Pessoa com Deficiência). 2015b. Disponível em: http://www.planalto.gov.br/ccivil_03/_Ato2015-2018/2015/Lei/L13146.htm. Acesso em: 22 fev 2016.

BRASIL. Ministério da Educação e do Desporto. Portaria 1793, de dezembro de 1994. Recomenda a inclusão da disciplina ou conteúdos sobre aspectos ético-políticopedagógicoeducacionais da normalização e integração da pessoa portadora de necessidades especiais em cursos de graduação. 1994. Disponível em:

http://portal.mec.gov.br/seesp/arquivos/pdf/port1793.pdf. Acesso em: 6 fev. 2011.

BRASIL. Política Nacional de Educação Especial na perspectiva da Educação Inclusiva. MEC/SEESP: Brasília, 2008a. Acesso em: Disponível em:

http://portal.mec.gov.br/seesp/arquivos/pdf/politica.pdf. Acesso em: 07 fev. 2011.

BRASIL. Resolução n⿳ 2, de $\mathbf{1}^{\mathbf{0}}$ de julho de 2015. Define as Diretrizes Curriculares Nacionais para a formação inicial em nível superior (cursos de licenciatura, cursos de formação pedagógica para graduados e cursos de segunda licenciatura) e para a formação continuada. 2015a. Disponível em:

http://portal.mec.gov.br/index.php?option=com_docman\&view=download\&alias=70431-res- 
cne-cp-002-03072015-pdf\&category_slug=agosto-2017-pdf\&Itemid=30192. Acesso em: 16 fev. 2018.

CARDOSO, C. R. Organização do trabalho pedagógico, funcionamento e avaliação no Atendimento Educacional Especializado em Salas de Recursos Multifuncionais. 2013. 189 f. Dissertação (Mestrado em Educação) - Programa de Pós-graduação em Educação, Universidade Federal de Goiás- Regional Catalão, Catalão, 2013.

INSTITUTO EDUCACIONAL DE ESTUDOS E PESQUISAS EDUCACIONAIS ANÍSIO TEIXEIRA. Sinopse estatística da educação básica 2016. Brasília: Inep, 2017. Disponível em: http://portal.inep.gov.br/sinopses-estatistitcas-da-educacao-báscia. Acesso em: 27 fev. 2018.

INSTITUTO NACIONAL DE ESTUDOS E PESQUISAS EDUCACIONAIS ANÍSIO TEIXEIRA. Sinopse Estatística da Educação Básica. Brasília, 2015, Disponível em: http://portal.inep.gov.br/web/guest/sinopses-estatisticas-da-educacao-basica. Acesso em: 04 jan. 2018.

MARCONI, M. A.; LAKATOS, E. M. Fundamentos de metodologia científica. 5. ed. São Paulo: Atlas, 2003.

MOREIRA, L. C.; BOLSANELLO, L. A.; SEGER, R. G. Ingresso e permanência na Universidade: alunos com deficiência em foco. Educar em Revista, Curitiba, n. 41, p. 125143, 2001.

NOZI, G. S.; VITALIANO, C. R. Saberes de professores propícios à inclusão dos alunos com necessidades educacionais especiais: condições para sua construção. Revista Educação Especial, Santa Maria, v. 30, n. 59, p. 589-602, set./dez. 2017.

POKER, R. B.; MELLO, A. R. L. Inclusão e formação do professor. Journal of Research in Special Educational Needs, v. 16, n. 1, p. 619- 624, 2016.

PUREZA, M. G. B. Desvelando o território da educação inclusiva na formação inical de professores de Geografia: os projetos pedagógicos da UFPA e IFPA em análise. 2012. 200f. Dissertação (Mestrado em Educação) Programa de Pós-Graduação em Educação,

Universidade Federal do Pará, Belém, 2012.

RIBEIRO, E. B. V. Formação de professor de Ciências e Educação Inclusiva em uma instituição de ensino superior de Jataí-GO. 2011. 107f. Dissertação (Mestrado em Educação, Ciências e Matemática) - Programa de pós-graduação em Educação em Ciências e Matemática, Universidade Federal de Goiás.

SALVADOR, D. A. Métodos e técnicas de pesquisa bibliográfica. 11. ed. São Paulo: Sulinas, 1986.

SANTOS, Y. B. S. O paradigma da inclusão no curso de pedagogia do IFPA: o projeto formativo em debate. 2012. 152f. Dissertação (Mestrado em Educação). Programa de PósGraduação em Educação da Universidade Federal do Pará, Belém, 2012. 
SILVA, L. C. da. Políticas públicas e formação de professores: vozes e vieses da educação inclusiva. 2009. 251. Tese (Doutorado em Educação) - Faculdade de Educação, Universidade Federal de Uberlândia, Uberlândia, 2009.

SILVA, M. R. A Formação de Professores de Atendimento Educacional Especializado de Goiás. 2014. 194 f. Dissertação (Mestrado em Educação) - Programa de Pós-Graduação em Educação, Universidade Federal de Goiás - Regional Catalão, Catalão.

UNESCO. United Nations Educational, Scientific na Cutural Organization (1994). The Salamanca Statement an Framework for Anction Special Needs Education. Salamanca, 1994.

VEIGA, I. P. A. Inovações e projeto político-pedagógico: uma relação regulatória ou emancipatória? Cad. Cedes, Campinas, v.23, n. 61, p. 267-281, 2003.

VITALIANO, C. R.; MANZINI, E. J. A formação inicial de professores para a inclusão de alunos com necessidades educacionais especiais. In: VITALIANO, C. R.; MANZINI, E. J. A. Formação de professores para a inclusão de alunos com necessidades educacionais especiais. Londrina: EDUEL, 2010. p. 49-112.

\section{Como referenciar este artigo}

BORGES, Wanessa Ferreira.; SANTOS, Cristiane da Silva.; COSTA, Maria da Piedade Resende da. Educação Especial e formação de professores: uma análise dos projetos pedagógicos de curso (PPC). Revista Ibero-Americana de Estudos em Educação, Araraquara, v. 14, n. 1, p. 138-156, jan./mar., 2019. E-ISSN: 1982-5587. DOI: 10.21723/riaee.v14i1.11067.

Submissão: 03/04/2018

Revisões requeridas: 26/07/2018

Aprovação final: 30/10/2018 